\title{
Más allá de la imagen. La literatura visual del artista invisible
}

\author{
Beyond the image. 'The invisible artist's visual literature
}

\author{
David MARQués SERra \\ dmarques@easdcastello.org
}

EASD Castelló

\begin{abstract}
Resumen: El presente artículo gira en torno al proceso constructivo de la comunicación pictórica contemporánea en el caso de la producción de Joan Millet (Gandía, 1958). Así pues, en él se abordan diferentes cuestiones que se devienen esenciales para la configuración de su particular discurso, tales como la intención narrativa primigenia, la estructura semiótica de la imagen o el valor expresivo de la propia materia. Entender la conjunción entre lo narrativo y lo sensitivo resulta primordial para la comprensión de la intencionalidad del artista en cuestión, que siempre articula sus imágenes minuciosamente, atendiendo y sirviéndose de cualquier recurso compositivo, literario o experiencial que esté a su alcance. Además, también se hace hincapié en la posición que ocupa el posible espectador en el rodeo comunicativo que el artista inicia con la obra. Del receptor, en definitiva, es de quien depende el eventual salto hacia el plano simbólico.
\end{abstract}

Palabras clave: Pintura, narración, literatura, comunicación, bellas artes, arte contemporáneo

\begin{abstract}
This article revolves around the constructive process of contemporary pictorial communication in Joan Millet's production (Gandia, 1958). Thus, it addresses different issues that become essential for the configuration of his discourse, such as the original narrative intention, the semiotic structure of the image, or the expressive value of the subject itself. Understanding the conjunction between the narrative and the sensitive is paramount to the comprehension of the artist's intention, as he always articulates his images meticulously, attending and using any compositional, literary, or experiential resource in his reach. Emphasis is placed on the position of the potential viewer in the communicative exchange that the artist begins with his work, hence being the receiver the one on whom the eventual jump to the symbolic level depends.
\end{abstract}

Keywords: Painting, narration, literature, comunication, fine arts, contemporary art 


\section{Introducción: Acercamiento a la actitud de comunicación pictórica}

[...] sólo las formas pueden ser comunes, pero no los contenidos.

(Lévi-Straus 1964: 102)

El hecho de situarnos frente a una obra pictórica y contemplarla in situ supone, en principio, un encuentro comunicativo que oscila entre los sentidos y el pensamiento, entre la transmisión sensible y el potencial sentido narrativo, bien inoculado por el propio autor o bien descifrado por el supuestamente atrevido concurrente. La pintura, de aspecto mayormente bidimensional, juega con la simulación y las múltiples interpretaciones ópticas e imaginales, la ilusión es su campo expansivo. Así pues, como sucede en cualquier acto de transmisión de información, requiere de un espectador predispuesto a impregnarse, a succionar la sustancia que de ella se desprende con mayor o menor vehemencia, con agresividad o bien con delicada sutileza. En cualquier caso, el acto comunicativo realizado a través de las imágenes creadas sigue siendo una relación entre dos mentes, una de las cuales permanece suspendida, atrapada en esa ventana temporal que llamamos cuadro.

El tiempo, por lo tanto, resulta significante en el vínculo de la dicotomía emisor-receptor, porque es el elemento esencial para la configuración del contexto interpretativo, quizás por estar capacitado para albergar y mantener toda referencia sociocultural que se pueda dar en la mente detonante. Según Jean-François Martel: «El arte es un tipo de alquimia: transforma el material de partida en algo completamente nuevo. Pero, a diferencia del alquimista que buscaba transmutar el plomo en oro, el artista transforma los signos en símbolos» (2015: 70) Así, cuando un espectador se acerca a contemplar una obra, el entramado de signos en ella encarcelado, que persiste latente al igual que la espada permanecía impasible sobre la cabeza de Damocles, se desencadena, se desploma sobre el intelecto del curioso observador. De este modo, el signo se deviene susceptible de ser convertido en símbolo y aquello que se representa en la superficie bidimensional del soporte, que alude a un elemento presente en la realidad humana -de manera genérica- pasa a concretarse a través del sistema nervioso del sujeto específico que mira, de sus vivencias, de sus referencias, de su contexto particular.

Todo arte es a la vez superficie y símbolo.

Por eso, los que entran debajo la superficie lo hacen por su cuenta y riesgo.

Por eso, los que leen el símbolo lo hacen por su cuenta y riesgo.

Es el espectador, y no la vida, lo que realmente refleja el arte. (Wilde 2019: 24) 


\section{Semiótica de lo sensorial y narrativo en el caso del artista invisible Joan Millet}

La apuesta por una producción artística de talante narrativo conlleva, consecuentemente, el deseo comunicativo de una manera mucho más específica, a través de un camino que, en cierto modo, se presenta restringido en algunos aspectos, con la intención de encauzar al asistente en el acto interpretativo, si, finalmente, éste decide ceder a la comunicación que se le brinda. En el caso de la obra pictórica de nuestro artista invisible, Joan Millet, nacido en Gandía el 1958 (Marqués 2017), la percepción se produce a dos niveles: por un lado, el entramado narrativo que se corresponde con la necesidad de contar una historia; y, por otro lado, el aspecto sensitivo, pictórico, que es testigo de las emociones del pintor expresionista, a modo de registro directo de una vivencia muy concreta.

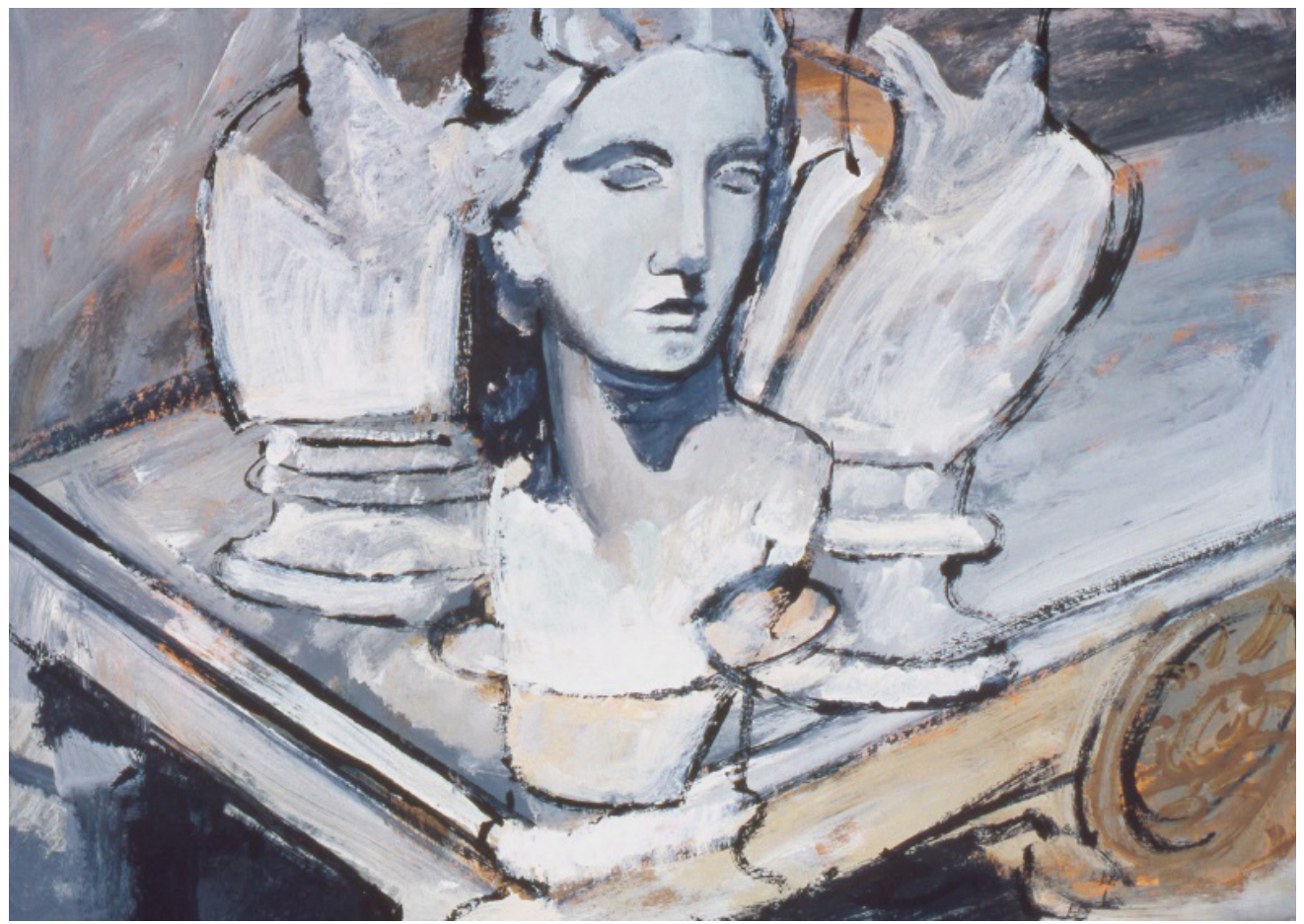

Fig 1. Picabia oui, Magritte non. Je le regrette! . Millet (1994)

El hecho de haber analizado la obra completa de Millet nos ha proporcionado conciencia suficiente sobre sus intenciones, así como sobre el procedimiento plástico-conceptual que les otorga la posibilidad de existir tal y como se nos presentan. Y, precisamente, nuestro afán por remitirnos al origen de su quehacer creativo, nos lleva a las pretensiones narrativas a las que nos hemos ya referido con anterioridad. De tal suerte, encontramos en la carrera artística de nuestro autor una serie de pinturas, previas a la ejecución objetual que le ha caracterizado con el tiempo, ante las que nos resulta interesante detenernos y, sobretodo, atender a sus correspondientes títulos. Es la curiosidad quien nos guía y nos obliga a reparar en las inscripciones que acompañan a estos cuadros, muchas veces caligrafiadas sobre los mismos, a modo de reivindicación, de necesidad de 
atención por parte de la retina que visualiza una pieza determinada. Y ese texto acompañante, que no parece responder a un mero recurso literario o poético, es el que nos incita, justamente, a realizar los presentes apuntes sobre este trabajo en cuestión, con el fin de esclarecer, de arrojar algo de luz sobre la posible correspondencia entre la palabra y la representación en el caso que nos concierne.

Roland Barthes, en su libro Lo obvio y lo obtuso, aludiendo a las letras ilustradas que Massin recoge, dilucida sobre la autosuficiencia de un único carácter capaz de funcionar como grafema con finalidad en sí mismo, con lo cual, apunta hacia la posibilidad de que el signo contenga, también, un significado concreto, de acción artística: «El alfabeto constituye un sistema autónomo y, en este caso, provisto de los suficientes predicados como para garantizar su individualidad» (1986:104) nos dice el autor francés con convencimiento tras apuntar lo siguiente:

[...] por un lado, la letra «comprime» el lenguaje, a todo lenguaje escrito, con el cepo de sus veintiséis caracteres -en francés-, que no son más que una simple combinación de rectas y curvas; pero, por otro lado, constituye el punto de partida de una imaginería tan vasta como una cosmografía. (Barthes 1986: 103)
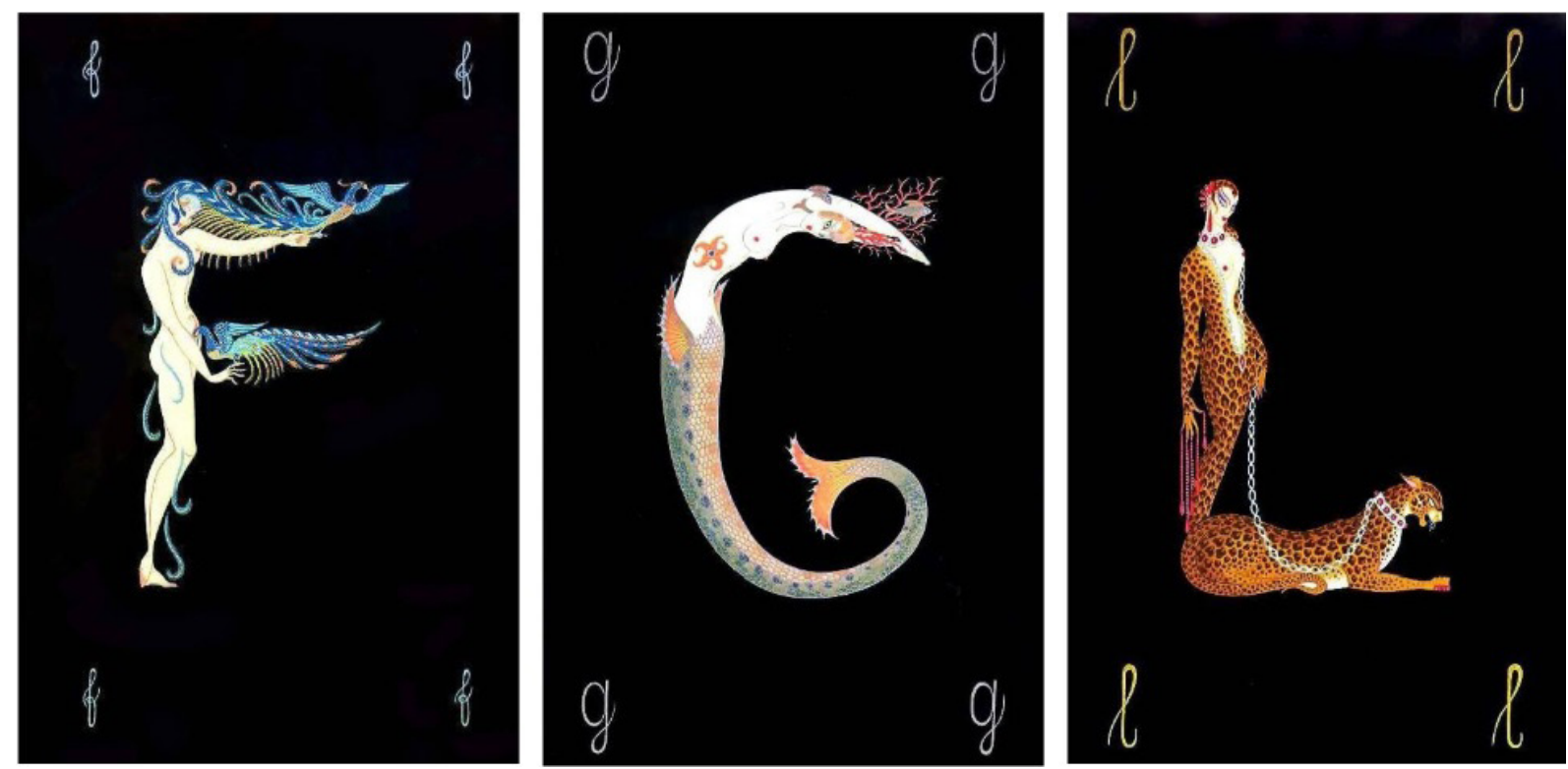

Fig 2.: Alphabet Suite. Erté (1927-1957)

Sin embargo, y en contraste con esta suposición de Barthes aplicada a ilustraciones de abecedarios como el de Romain de Tirtoff, más conocido como Erté, hemos de decir que Joan Millet se mantiene aún por la senda comunicativa en la cual la letra siempre aparece articulada y vinculada a un significado preciso y exento de su morfología estética. En el caso que nos ocupa, el carácter no se libera de su papel lingüístico y es destinado a retro-complementarse con la imagen. Decimos retro-complementarse porque, al parecer, en las obras pictóricas de nuestro autor invisible, al igual 
que sucede en su prolongación objetual, la atracción visual proporciona el impacto inmediato y es subsiguientemente, en el caso de suscitar interés suficiente en el receptor, cuando se desvía la mente hacia el epígrafe con el objetivo de encontrar allí algún indicio del camino adecuado con el cual iniciar el recorrido intelectual. Tratamos de advertir con ello que el título, después de una primera aproximación retiniana, exige atención y vuelve a remitir la mirada hacia la obra, una mirada que, tras esta explicada acción circular, queda ya impregnada de subjetividad externa, procedente de la mente del propio autor. El visitante, subsiguientemente, si lo de desea, puede adentrarse y realizar una interpretación simbólica que se verá inevitablemente condicionada por los signos que configuran la totalidad: la pintura y el texto. Procede recordar, a propósito de lo anterior, la definición de símbolo que nos ofrece Carl Gustav Jung: «Lo que llamamos símbolo es un término, un nombre, o aún una pintura, que puede ser conocido en la vida diaria aunque posea connotaciones específicas además de su significado corriente y obvio.» (1995: 20)

\section{Apuntes en torno a la razón de las palabras que acompañan a la imagen}

Es el momento de referirse ahora a René Magritte, que con sus títulos parece haber obsequiado a la crítica, a la filosofía y al pensamiento moderno, con un punto de apoyo desde el cual catapultar especulaciones en torno a la imagen, la idea y su representación, generando así una comprensible distorsión de la naturaleza per sé de semejantes creaciones plásticas. No obstante, de un modo u otro, la importancia de los epígrafes en la producción de Magritte se presenta primordial y, a tal efecto, resulta competencia nuestra meditar en torno a ello con la finalidad de relacionarlo con la producción que abordamos, cuyas inscripciones acompañantes se manifiestan, igualmente, fundamentales.

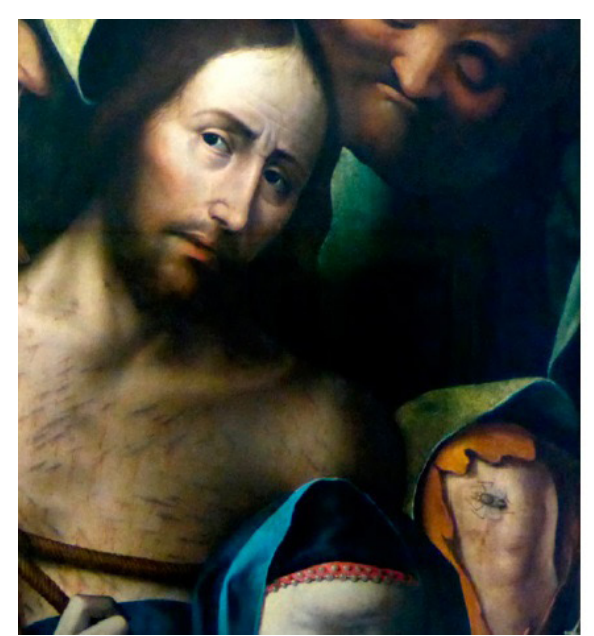

Fig 3. La Pasión de Cristo (detalle).

El Bosco (1510-1515)

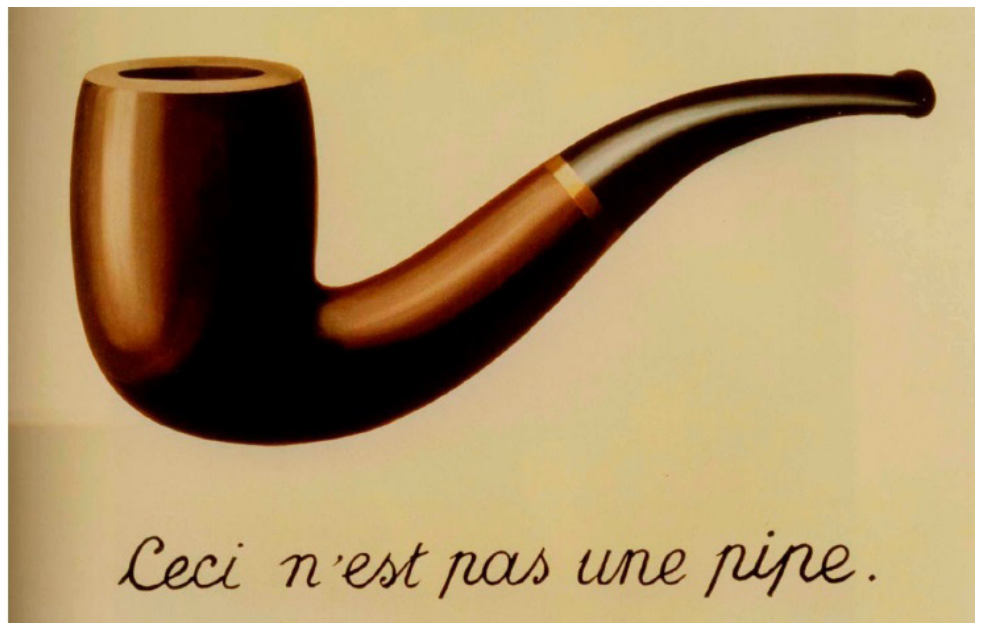

Fig 4. La traición de las imágenes. Magritte (1929) 
Hablemos entonces de su emblemática pieza titulada La traición de las imágenes (1929); efectivamente, la famosa pipa que no es una pipa. Primeramente, cabe considerar la existencia de una diferencia abismal entre una pintura y la realidad propiamente dicha, entre otras cosas porque no nos situamos en la Antigua Grecia de Zeuxis y Parrasio ${ }^{116}$ (Plinio 35: 65), donde la apariencia de realidad en un trabajo pictórico era sinónimo de aptitud. La dilatada tradición artística occidental, asociada con la implacable decisión del tiempo, se ha encargado de configurar ciertos valores inherentes al medio, sean expresivos, técnicos o de elaboración representativa, llegando a la conclusión de que una pintura es una pintura y la realidad es otra cuestión muy distinta; no comparten esencia alguna. En atención a lo cual, se trasluce notoriamente que la representación pictórica no es la objetividad misma, pues juega con su lenguaje de figuración bidimensional y no con el idioma de la realidad. Así pues, en consecuencia, llegamos, en parte, a comprender la propiedad intrínseca de las palabras que acompañan a los cuadros de Magritte: se trata de una aportación claramente poética que se entretiene con la convivencia lírica mantenida por dos imágenes generalmente opuestas. La pipa no es una pipa, sino la representación de una pipa; el texto que la acompaña tampoco es una pipa, por tratarse de una sencilla sentencia; y la pintura, dicho sea de paso, de pretender ser una maniobra de confusión, resultaría un fracaso descriptivo, porque, tras observar el diseño de Andrea Pozzo para la nave central de San Ignacio de Loyola -Roma- de finales del siglo XVII, frescos que nos hacen confiar en lo increíble, cabría esperar de un pintor muy posterior cierto grado de naturalismo con mayor factura. Por otra parte, de no pretender la falsa ilusión en la representación ¿qué sentido tendría la citada frase tímidamente manuscrita? Aunque, también cabe reparar en que el artista nos presenta una pipa de grandes dimensiones, circunstancia que podría hacernos desconfiar de su existencia en el mundo tangible. Sin embargo, el tratarse de un utensilio realizado por y para el ser humano le otorga, asimismo, la posibilidad de existir como elemento físico.

Parece ser, entonces, que el conflicto viene dado por la contradicción o la negación del todo, que, además, paradójicamente, también sugiere ciertas afirmaciones. Jheronimus van Aken, comúnmente conocido como El Bosco, en un tríptico dedicado a La Pasión de Cristo (1510-1515), se adentra en una operación similar a la de la famosa pipa del aludido pintor belga, a principios del siglo XVI. Nos concierne la pieza diestra de tal composición, en la que queda soberbiamente representada la Flagelación de Cristo. En ella, un personaje situado en la sección derecha del cuadro muestra una rodilla desnuda sobre la cual, aposentada tranquilamente, parece frotarse las extremidades una mosca, de desmedidas dimensiones si la comparamos con un ejemplar vivo. Se agranda, entonces, el tamaño de semejante insecto, quizás con el fin último de evidenciar su irrealidad ante un curioso observador que, por el contrario, siente la misma repugnancia, una sensación auténtica, frente al

116 N. del A.: Se refiere al mito descrito por Plinio el Viejo, anécdota que aparece en Plinio 35: 65 y fue tomada asimismo de la obra de Duris, como ha demostrado claramente la investigación filológica. La historia es esta: Zeuxis pintó unas uvas y algunos gorriones acudieron a picotearlas. Entonces, Parrasio le rogó que le acompañara a su estudio, donde le demostraría que también él podía hacer algo similar. Una vez allí, Zeuxis pidió a Parrasio que descorriese la cortina que cubría la pintura. Pero la cortina era una pintura. Así, Zeuxis admitió la superioridad de Parrasio diciendo: «Yo engañé a los gorriones, pero he sido engañado por ti.» 
invertebrado en cuestión, aun siendo simplemente una apariencia. Lo hace El Bosco sin necesidad de ningún mensaje caligrafiado que nos aclare la ficción de aquello, a pesar de su naturalismo descriptivo, simplemente aumentando la medida de algo que se supone invariable, creado por la Naturaleza; nos hallamos ante una contorsión visual de mayor elegancia. Queda de manifiesto, de tal modo, que Magritte confiere más envergadura a las palabras que a la pintura en sí. En él, parece predominar la idea, eternamente relacionada con el pensamiento y, por consiguiente, con la expresión verbal. Sus piezas, en definitiva, sugieren mantener cierta preeminencia por lo filosófico y, de hecho, podríamos describirlas como ocurrencias de carácter reflexivo y apariencia poética.

Por el contrario, volviendo al caso de Millet, la pintura de éste cuenta con una autosuficiencia, al contener un valor expresivo propio del medio empleado. Pero, incluso con ello, su creación pictórica siempre nace de una idea previa, va ligada a ésta, concepto que se transmite, además, mediante el título otorgado, estableciéndose así entre imagen y texto una relación de equivalencia; porque la imagen responde a las necesidades de expresión plástica y el título a las de expresión narrativa. Ambas necesidades encuentran en su punto de fusión el lugar común idóneo desde el cual proyectarse hacia el mundo exterior, a cualquier posible espectador predispuesto.

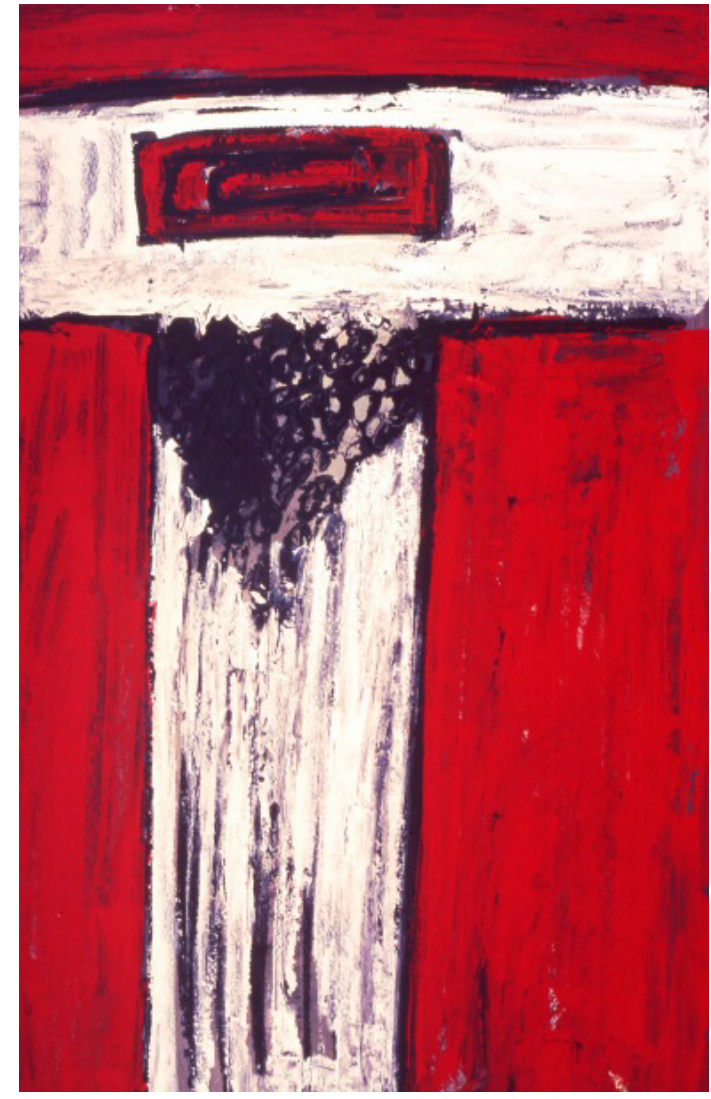

Fig 5.: J'espère que les enterrements des présidents sovietiques ne changent jamais. Millet (1991)

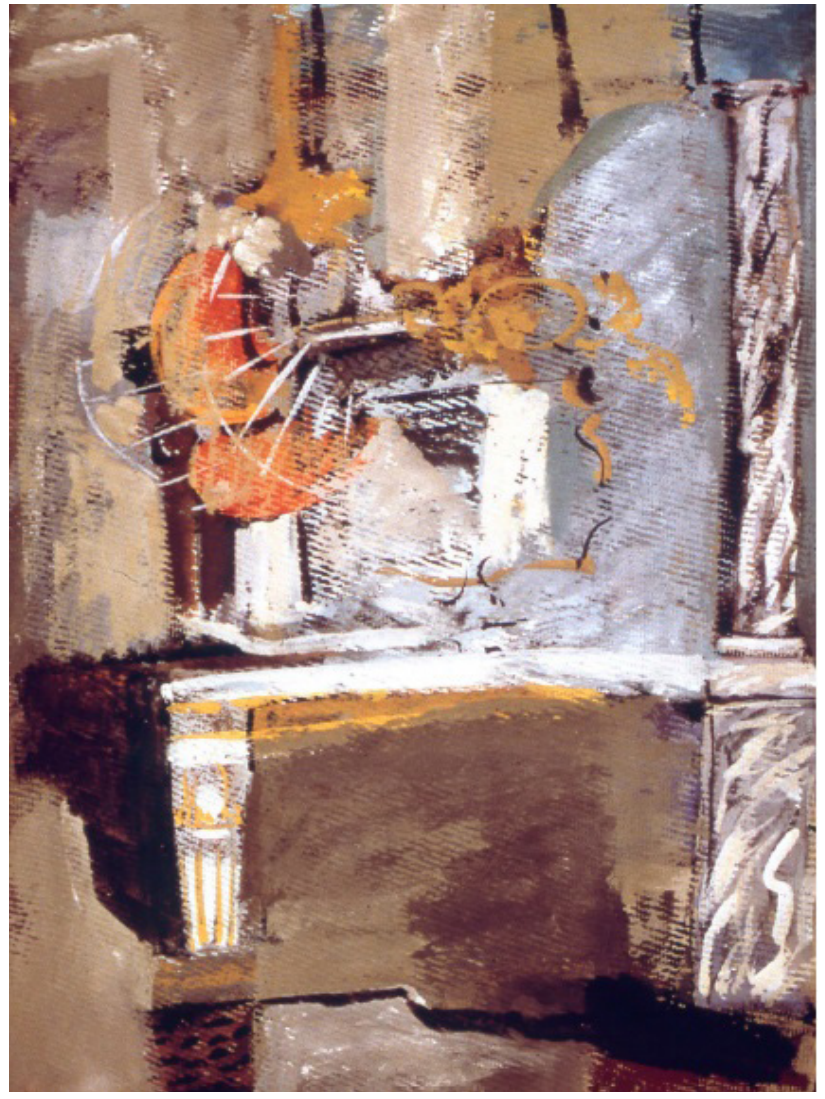

Fig 6.: Regarde, c'est chouette, le ventilateur sur la console Louis XVI. Sans la Révolution cela n'aurait pas été posible. Millet (1987) 
Nace la obra de Millet, como ya hemos apuntado, de una desazón por narrar, génesis, asimismo, de la correlativa configuración formal. De modo que lo primero, en este acto comunicativo, radica en la transmisión de una idea concreta, previa, porque es también previa a la forma, es decir, transita con anterioridad por el cerebro para luego ser concebida, materializada. Esta estimación, que parece algo confusa, queda, a nuestro juicio, perfectamente resumida en las siguientes palabras de Chirbes, al incidir en su propio proceder creativo:

\begin{abstract}
La urgencia por contar algo, que casi nunca es más que un malestar conmigo mismo, un desorden interno -que tiene que ver con el desorden que me rodea, y del que siento que formo, de algún modo, parte-, se impone poco a poco y, después de innumerables tanteos, encuentro el lugar desde el que el libro mira las cosas, y, a partir de ahí, la voz que las dice, el ritmo y la tensión con que las cuenta, el paso de la frase y el peso de cada capítulo. Me descubro contando una historia (2002: 69).
\end{abstract}

La morfología de los títulos proporcionados por Millet, debido a su propósito orientativo intrínseco, resulta un tanto inusual. Encontramos en este sentido algunos exponentes de cualidad extremadamente clarificadora. Es el caso, por ejemplo de Chien bourgois en partegeant gâteau avec sa maîtresse. Observez, elle porte une robe de Valentino -Perro burgués compartiendo pastel con su dueña. Fíese que ella lleva un traje de Valentino (1994). El énfasis con que se incide en determinadas cuestiones relativas a la composición de dicha inscripción, aquellas que transcurren inadvertidas por la superficie pictórica de la obra, nos cuentan lo que permanece oculto en una primera visualización, es decir, revelan el camino por el que emprender el tránsito. En este caso señalado, se precisa de una nota sugestiva que detenga nuestra atención en algunos puntos primordiales, como en el hecho de que la protagonista se arrope entre un vestido diseñado por Valentino, concreción que se encarga de constatar un estatus social, así como un determinado gusto; o bien que recalque la acción de malcriar al perro, mimo insinuado por la permisividad de la ingestión de dulces a la criatura canina, deglución que, además, no aparenta demasiado saludable aunque sí gratificante.

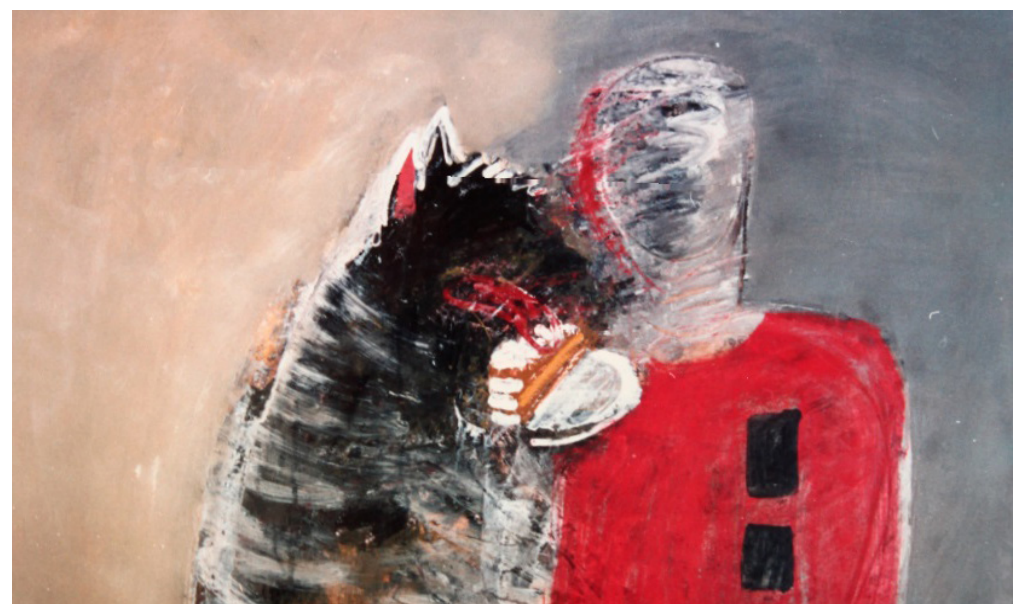

Fig 7.: Chien bourgois en partegeant gâteau avec sa maîtresse. Observez, elle porte une robe de Valentino. Millet (1994) 


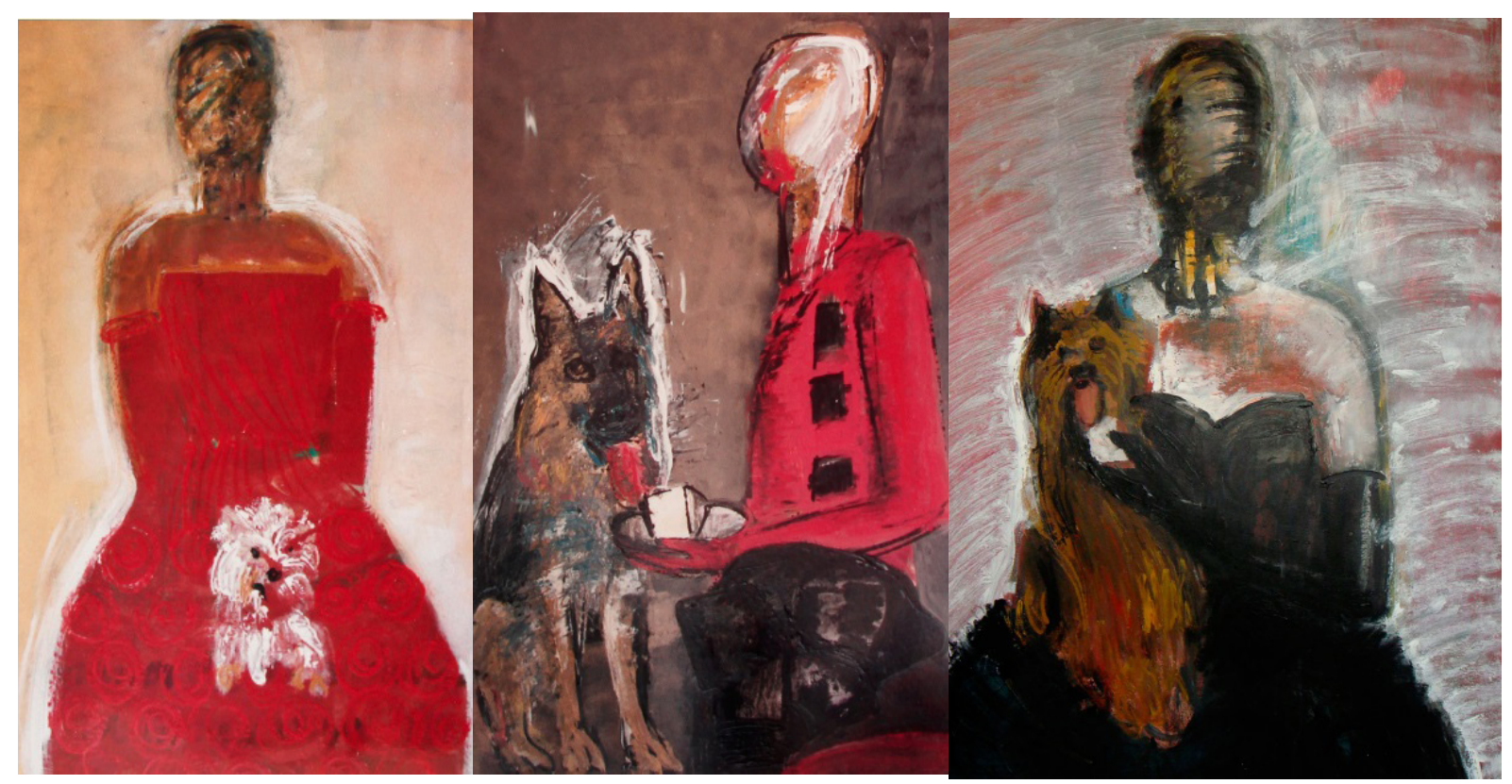

Fig 8.: Chien bourgois en partegeant gâteau avec sa maîtresse. Observez, elle porte une robe de Valentino. Millet (1994)

Procedemos, a continuación, a enumerar una selección de títulos con la intención de hacer tangible en el lector aquello que tratamos de demostrar, confiando, mediante esta clasificación que funciona como resumen de la trayectoria pictórica de Joan Millet, en hacerle tomar consciencia de nuestras conjeturas:

- Dépuis que tu soufflés de la colle, ta maison est devenue un enfer-Desde que esnifas pegamento, tu casa se ha convertido en un infierno.

- Project de fontaine pour le jardín du Directeur Général du Nouveau Régime -Proyecto de fuente para jardín de Director General del Nuevo Régimen.

- Regarde, c'est chouette, le ventilateur sur la console Louis XVI. Sans la Révolution cela n'aurait pas été posible -¡Mira qué bien queda el ventilador sobre la consola Luis XVI! Sin la revolución no hubiera sido posible.

- Picabia oui, Magritte non. Je le regrette! -Picabia sí, Magritte no. ¡Lo siento!

- J'espère que les enterrements des présidents sovietiques ne changent jamais -Espero que los entierros de los presidentes rusos no cambien jamás.

- Les salauds ne montent pas les escaliers, ils naissent dejà là-baut-Los hijos de puta no suben las escaleras, nacen para estar arriba. 

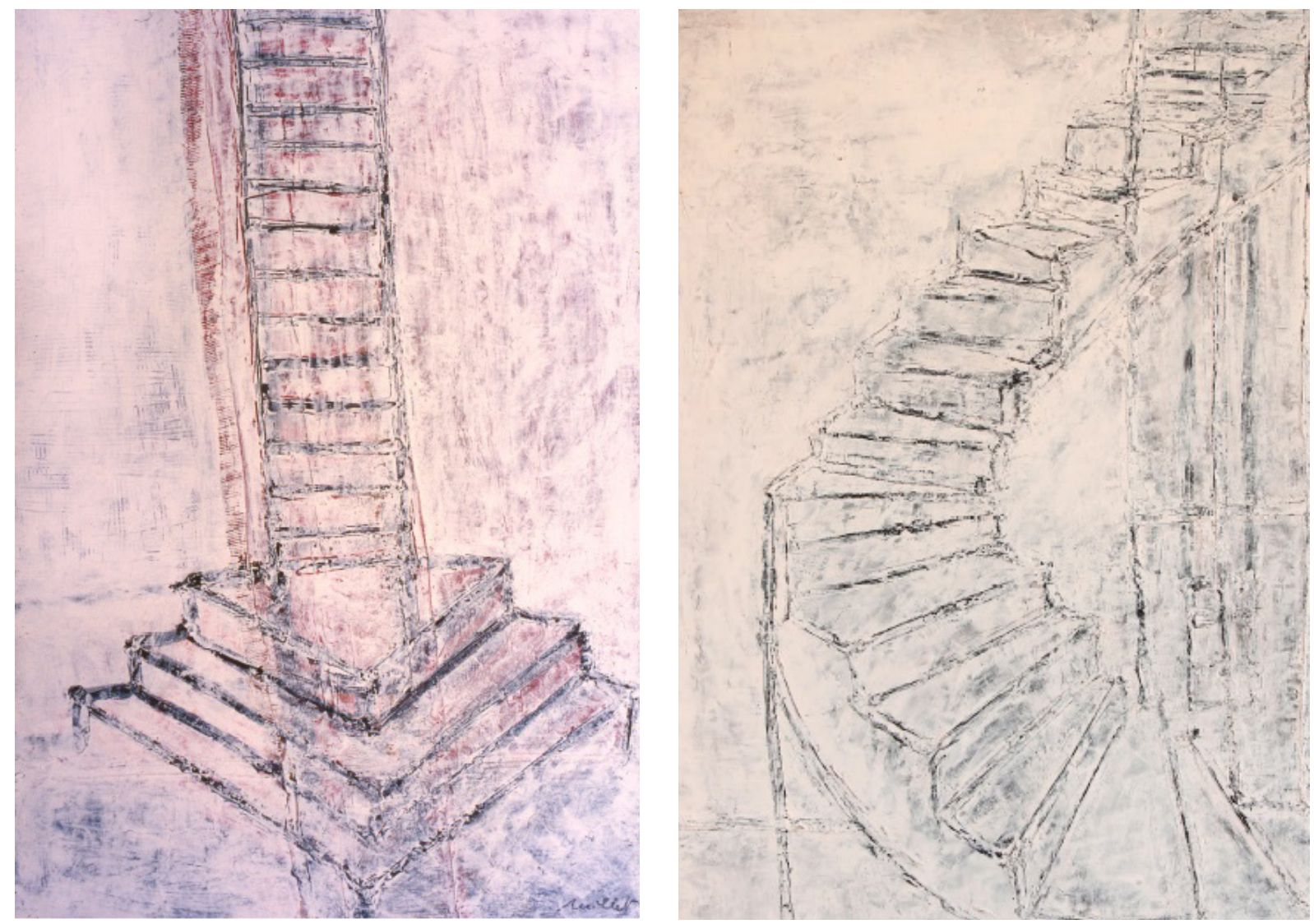

Fig 9.: Les salauds ne montent pas les escaliers, ils naissent dejà là-haut. Millet (1992)

Tanto el título que hemos empleado en calidad de ejemplo clarificador, como los dos últimos que aparecen registrados en la lista previa a las presentes palabras, pertenecen a una producción seriada. Quiere decir esto que se ha reincidido, pictóricamente, sobre una misma idea, afianzándola y proporcionándole, en ciertos aspectos, una solidez capaz de otorgarle mayor credibilidad. Esta insistencia reiterada, intermitente, de algún modo deja entrever la sospecha de que únicamente existe un camino narrativo por el que comenzar el viaje comprensivo. No estamos de acuerdo, en absoluto, con las suposiciones de Roland Barthes aplicadas a nuestro caso particular, pues, como es natural, carecen de autoridad universal.

Como es evidente, no se trata de restringir la escritura del cuadro a la crítica profesional de la pintura. El cuadro, escriba quien escriba, no existe sino en el relato que se hace de él; es más: en la suma y organización de sus lecturas que de él pueden hacerse: un cuadro nunca es otra cosa que su propia descripción plural. (1986: 154)

Rebatiendo lo anterior, diremos que, en el asunto específico de la indagación en la que estamos inmersos, concerniente a las intenciones pictórico-narrativas de nuestro autor invisible, al posible 
espectador se le presenta exclusivamente una disyuntiva. Elección que radica entre tomar la senda narrativa, citada con anterioridad, como punto de partida o bien permanecer en el deleite pictórico, dado que estas piezas en cuestión, a las que aludimos, cuentan, asimismo, con el extracto de una vasta tradición artística occidental; aquella que ha sobrevivido al tiempo y, en consecuencia, ofrece cierta calidad plástica al receptor. Esa primera vía, que coarta igualmente el albedrío del propio autor y, por tanto, también la apariencia pictórica, es la encargada de dictaminar, en gran parte, las relaciones formales y cromáticas que conforman la obra final; únicamente cabe observar la similitud individual que comparten los ejemplares de una misma serie, como es el caso de J'espère que les enterrements des présidents sovietiques ne changent jamais -Espero que los entierros de los presidentes rusos no cambien jamás (1991). Luego esta decisión, que es narrativa, compete a la necesidad individual del artífice que pretende guiar la mirada por un camino determinado, y entendemos que no debiera ser mancillada por la imaginación de un espectador creativo con afán de protagonismo. De producirse tal enfrentamiento inapropiado, que por otro lado sería válido pero no se traduciría en una interpretación idónea, quedaría desvanecido cualquier acto comunicativo, iniciado, forzosamente, con un mensaje en boca del emisor, aportación que resulta muy concreta en la obra de Millet. Además, puesto que aquí abordamos una indagación de carácter académico, nos corresponde centrarnos en las intenciones más legítimas.

Ya no es la obra, por cierto, lo que se lee, son los pensamientos de todos que vuelven a ser pensados, los hábitos comunes que se vuelven habituales, el vaivén cotidiano que sigue tejiendo la trama de los días: movimiento muy importante en sí mismo que no conviene desacreditar, pero en el que no están presentes ni la obra de arte ni la lectura (Blanchot 2004: 85).

Leyendo a Maurice Blanchot se nos pronuncia la cuestión que delibera acerca de la ubicación de nuestro familiarizado concurrente, el receptor. Lógicamente, a pesar de lo restrictivos que puedan haber resultado nuestros razonamientos, cabe esperar del citado espectador un grado de actuación propio del sistema comunicativo, pero, naturalmente, ceñido a la temática propuesta desde un inicio, aunque de ella surjan in situ fructuosas deducciones que se arrojen hacia temas externos, siempre, de algún modo, vinculados. Se precisa, por consiguiente, un espacio libre, de intercambio de información e ideas, una dimensión que se corresponda con el eterno retorno entre la imagen y la asimilación del título propuesto, en la cual tenga lugar la discusión necesaria entre ambos extremos de un segmento comunicativo. Ese lugar de incertidumbres parece el elegido para mantener una conversación lo suficientemente capacitada como para volver comprensible una totalidad: la obra de arte observada. Según las palabras de Maurice Blanchot:

Hablar es establecerse en ese punto donde la palabra tiene necesidad del espacio para resonar y ser oída, y donde el espacio, al convertirse en el movimiento mismo de la palabra, se convierte en la profundidad y la vibración de la mediación (Blanchot 2004: 132). 
Por lo tanto, se le desplaza solamente la justa responsabilidad a dicho concurrente, pues depositar en él mayor cometido respondería, como hemos apuntalado ya previamente, a una contradicción de transmisión. Procede entonces al propio autor decidir la cuantía de insinuaciones, de signos puestos al servicio del público, desde los cuales iniciar la posible conversación. Y la manera de ejecutar tal operación, en nuestro caso, radica en los epígrafes, fieles a las imágenes pictóricas. Se trata de una especie de declaración de intenciones propulsada por un retorcimiento obstinado en materia de títulos, incisivos y coherentes con el carácter trasgresor de un artista invisible.

\section{Consideraciones finales}

La ausencia de elementos que desvirtúan aquello que se pretende comunicar es evidente en la producción artística de Joan Millet. Los objetos anecdóticos no parecen tener cabida en sus escenarios y todo existe en las respectivas obras por una razón muy detallada. Este hecho, que descarta fulminantemente el horror vacui, supone, a su vez, una capacidad de síntesis que, en último término, resulta poética, retórica. E incluso cuando una multitud de elementos se representan de determinada manera con la finalidad última de ejercer la narración pertinente, estos parecen percibirse siempre como unidad. La elegancia distributiva, tanto formal como intelectual, la composición mental y la composición narrativa, precisan de concisión para su correcta transmisión. Cabe señalar que Millet siempre ha perseguido la difícil tarea de decir lo máximo posible, tanto morfológica como conceptualmente, con el mínimo registro; actitud que, inevitablemente, demuestra el grado de implicación y conjunción en lo que se refiere a la primera parte del acto comunicativo que es aquella que de él depende, la tarea de iniciar el enfrentamiento. Así pues, tras haber dilucidado acerca de la construcción del discurso pictórico-narrativo del autor y de comprender la razón de ser de los breves textos que acompañan cada obra, a nuestro parecer, podemos concluir diciendo que, en el caso concreto que nos ocupa, la literatura latente, en conjunción con el impacto retiniano de la pintura, configuran un espacio idóneo ante el cual poder reflexionar. Nos encontramos ante una simbiosis capaz de tejer el necesario entramado semiótico que permite al potencial espectador cuestionar los signos y, eventualmente, saltar hacia el plano de lo simbólico. Con esta intención, paralela e indirectamente se reivindica la presencia de un espectador consciente. 
David Marqués Serra. Más allá de la imagen. La literatura visual del artista invisible

\section{Bibliografía}

Barthes, R. (1986) Lo obvio y lo obtuso. Barcelona: Paidós.

Blanchot, M. (2004) El espacio literario. Barcelona: Paidós.

Chirbes, R. (2002) La buena letra. Barcelona: Anagrama.

Jung, C.G. (1995) El hombre y sus simbolos. Barcelona: Paidós.

Lévi-Strauss, C. (1964) Elpensamiento salvaje. México: Fondo de Cultura Económica.

Marqués, D. (2017) La plástica del objeto encontrado. Técnicas e ideología en el caso del artista invisible Joan Millet. Valencia: Universidad Politécnica de València. Tesis doctoral.

Martel, J. F., (2015) Vindicación del arte en la era del artificio. Girona: Atlanta.

Wilde, O. (2019) El retrato de Dorian Gray. Madrid: Siruela. Tiempo de clásicos. 